\title{
Recombinant Factor VII Activated and Prothrombin Complex Concentrate Use at a Tertiary Academic Medical Center
}

\author{
David P. Reardon · Paul M. Szumita • \\ Jean M. Connors · Julie K. Atay
}

Published online: 2 July 2014

(c) Springer Science+Business Media New York 2014

\begin{abstract}
To describe the use of recombinant Factor VII activated (rFVIIa) and three factor prothrombin complex concentrate (PCC3) in the absence of published guidelines, we conducted a single center, retrospective, observational study to evaluate the appropriate of use of rFVIIa and PCC3 therapy based on institution-specific guidelines, which were based on limited published data. Six patients received rFVIIa and 32 received $\mathrm{PCC} 3$ during the analysis period. rFVIIa and PCC3 were utilized appropriately in 100 and $91 \%$ of cases, respectively. rFVIIa indications included surgical bleeding (50\%), factor deficiency (33\%), and intracranial hemorrhage (17\%). PCC3 indications included warfarin-related intracranial hemorrhage $(47 \%)$, nonwarfarin-related intracranial hemorrhage $(16 \%)$, surgical bleeding (23\%), trauma (7\%), and other (7\%). PCC3 use was more common than rFVIIa use and was given with FFP and vitamin $\mathrm{K}$ for warfarin-related bleeding. The use of clotting factors for life-threatening hemorrhage should be reserved for institution-approved indications based on available literature and expert opinion.
\end{abstract}

\footnotetext{
D. P. Reardon $(\varangle)$ · P. M. Szumita · J. K. Atay

Department of Pharmacy, Brigham and Women's Hospital,

75 Francis Street, Boston, MA 02115, USA

e-mail: dpreardon@partners.org

P. M. Szumita

e-mail: pszumita@partners.org

J. K. Atay

e-mail: jatay@partners.org

J. M. Connors

Division of Hematology, Brigham and Women's Hospital,

75 Francis Street, Boston, MA 02115, USA

e-mail: jconnors@partners.org
}

Keywords Prothrombin complex concentrate . Recombinant factor VII activated · Clotting factors

\section{Introduction}

Trauma, surgery, and anticoagulant-related hemorrhage can produce life-threatening dysregulation of the natural clotting cascade $[1,2,3 \cdot 0]$. Major blood loss, defined as $>20 \%$ loss of total blood volume, is commonly associated with trauma, factor deficiencies, and surgical complications $[1,2]$. Traditionally, life-threatening bleeding has been treated with blood products [4]. Although use may only result in temporary stabilization, packed red blood cells, fresh frozen plasma, platelets, and cryoprecipitate are the cornerstones of therapy. In order to halt further bleeding, patients may require more targeted therapy, such as specialized products $[5 \cdot, 6-9]$. Two commonly used products are prothrombin complex concentrates (PCC) and recombinant Factor VII activated (rFVIIa) [1-4, 5•]. Extensive Use of these agents has not been widely described in literature, so clearly defined indications and dosing strategies beyond recommendations by the FDA are not available to guide prescribers and institutions.

PCC are pooled blood products that may contain clotting Factors II, VII, IX, X, and proteins $\mathrm{C}$ and $\mathrm{S}$, and thus promote activation of the clotting cascade at many different points $[1,3 \bullet \cdot]$. Proteins $\mathrm{C}$ and $\mathrm{S}$ have anticoagulant properties, acting to decrease thromboembolic events. There are currently three different types of PCC available. Activated PCC contains Factors II, IX, and X, and activated Factor VII. Three factor PCC (PCC3) contain non-activated Factors II, IX, X, and minimal amounts of Factor VII. Four factor PCC (PCC4) contain non-activated Factors II, VII, $\mathrm{IX}$, and $\mathrm{X}$, as well as the anticoagulant proteins $\mathrm{C}$ and $\mathrm{S}$. 
Prior to the availability of PCC4 in the United States, the Food and Drug Administration (FDA)-approved indications for PCC3 were solely for the prevention and treatment of bleeding in patients with Hemophilia B or Factor IX deficiency. However, PCC3 therapy is commonly employed to reverse anticoagulant-related bleeding, which has been published in many small studies, but not documented as an FDA-approved indication [1, 3••].

The FDA-approved rFVIIa for prophylaxis and treatment of acute bleeding and surgical-related bleeding in individuals with congenital FVII deficiency, hemophilia A or B with factor inhibitors, and individuals with acquired clotting deficiencies. However, rFVIIa is commonly administered offlabel in patients with risk factors for bleeding during trauma, neurosurgery, cardiac surgery, and liver transplantation, as well as for reversal of excessive anticoagulation [5•].

While several studies support the use of blood factors in patients with acute, life-threatening bleeding secondary to trauma, surgery, and anticoagulation-associated hemorrhage, PCC3, and rFVIIa have the potential for serious adverse events $[1,5 \bullet]$. Thoughtful selection of appropriate agents, doses, and candidates for therapy is necessary due to the acuity of situations requiring these agents and the potential for adverse events if used inappropriately. Due to small trials and inconsistent patient populations studied, no clearly defined standard of use has been established. The aim of our study was to describe PCC3 and rFVIIa use to determine appropriateness of therapy in routine clinical practice as defined by an institutional guideline crafted from limited available literature.

\section{Methods}

This was a single center retrospective, observational, descriptive study to determine the appropriateness of rFVIIa and PCC3 use compared to clinical practice guidelines. The PCC we used at our institution prior to FDA approval of PCC4 was a PCC3 (Profilnine SD ${ }^{\circledR}$ ). We identified consecutive adult patients who received $\mathrm{rFVIIa}$ and/or PCC3 between November 2011 and March 2012 through our electronic medical record. Institutional guidelines (Table 1) for rFVIIa and PCC3 indication and dose had been established and included both FDA-approved and -unapproved indications. The Brigham and Women's Hospital institutional review board approved this study prior to data collection.

Data were collected retrospectively from electronic and paper-based medical records.

Indication for use and dosing strategies was based on physician diagnosis documented in the record. The need for repeat dosing, as well as thrombotic and/or immunological reactions, was also recorded. Concomitant therapy, defined as blood products and vitamin $\mathrm{K}$, was assessed within specific indications to determine patterns of use.

Table 1 Institutional indications and doses of recombinant Factor VII activated and prothrombin complex concentrate

\begin{tabular}{|c|c|c|}
\hline & Indication & $\begin{array}{l}\text { Dose (based on actual } \\
\text { body weight) }\end{array}$ \\
\hline \multirow[t]{3}{*}{$\begin{array}{l}\text { Three factor prothrombin } \\
\text { complex concentrate }\end{array}$} & $\begin{array}{l}\text { The prevention and control of bleeding in patients with } \\
\text { Factor } 9 \text { deficiency due to hemophilia B. }\end{array}$ & $\begin{array}{l}\text { (Desired Factor IX activity- } \\
\text { current Factor IX activity) } \times \mathrm{kg}\end{array}$ \\
\hline & $\begin{array}{l}\text { The treatment of warfarin-related life-threatening } \\
\text { hemorrhage* }\end{array}$ & INR $<4: 25 \mathrm{U} / \mathrm{kg}$ INR $\geq 4: 50 \mathrm{U} / \mathrm{kg}$ \\
\hline & $\begin{array}{l}\text { Reversal of life-threatening bleeding in perioperative } \\
\text { patients due to acquired coagulopathy* }\end{array}$ & $25 \mathrm{U} / \mathrm{kg}$ \\
\hline \multirow[t]{5}{*}{ Recombinant Factor VII activated } & $\begin{array}{l}\text { Prevention and management of acute bleeding episodes } \\
\text { in patients with congenital Factor } 7 \text { deficiency }\end{array}$ & $20 \mu \mathrm{g} / \mathrm{kg}$ \\
\hline & $\begin{array}{l}\text { Uncontrolled bleeding associated with trauma or } \\
\text { surgery in which no clear surgical source of bleeding } \\
\text { can be identified* }\end{array}$ & $40 \mu \mathrm{g} / \mathrm{kg}$ \\
\hline & $\begin{array}{l}\text { Salvage therapy for uncontrolled bleeding not } \\
\text { responsive to conventional therapy and/or PCC3* }\end{array}$ & $40 \mu \mathrm{g} / \mathrm{kg}$ \\
\hline & $\begin{array}{l}\text { Acute intracranial hemorrhaging in patients not } \\
\text { receiving warfarin therapy* }\end{array}$ & $40 \mu \mathrm{g} / \mathrm{kg}$ \\
\hline & $\begin{array}{l}\text { Prevention and management of bleeding in surgical } \\
\text { interventions or invasive procedures for patients with } \\
\text { hemophilia A or B with inhibitors to Factor } 8 \text { or } \\
\text { Factor } 9 \text { and in patients with acquired hemophilia }\end{array}$ & $90 \mu \mathrm{g} / \mathrm{kg}$ \\
\hline
\end{tabular}

* Non-FDA-approved indications

PCC3 three factor prothrombin complex concentrate 
Table 2 Baseline patient demographics

\begin{tabular}{lll}
\hline & PCC3 $(N=32)$ & rFVIIa $(N=6)$ \\
\hline Age (years) & $68.6 \pm 18$ & $57.2 \pm 19.9$ \\
Male sex, $N(\%)$ & $17(53)$ & $4(67)$ \\
Actual body weight $(\mathrm{kg})$ & $79.1 \pm 21.7$ & $74.7 \pm 13$ \\
In hospital mortality, $N(\%)$ & $8(25)$ & $2(33)$ \\
Hospital length of stay (days) & $10(6-14)$ & $6(3-9)$ \\
INR & $2.3(1.7-2.7)$ & $1.45(1.1-1.8)$ \\
aPTT & $39.4(33.7-45.5)$ & $46.9(34.9-62.1)$ \\
\hline
\end{tabular}

PCC3 three factor prothrombin complex concentrate; rFVIIa recombinant Factor VII activated

Table 3 Dosing and indications for therapy

\begin{tabular}{lll}
\hline & PCC3 & rFVIIa \\
\hline Dose & $2191 \pm 836 \mathrm{U}$ & $3.5 \pm 3.3 \mathrm{mg}$ \\
Dose/kg (ABW) & $27.6 \pm 7.4 \mathrm{U} / \mathrm{kg}$ & $43.1 \pm 30.3 \mathrm{mcg} / \mathrm{kg}$ \\
Repeat dose, $n(\%)$ & $1(3.1)$ & $2(33.3)$ \\
Indication for therapy, $n(\%)$ & \\
ICH on AC & $18(56.2)$ & $1(16.7)$ \\
ICH not on AC & $1(3.1)$ & $0(0)$ \\
Cardiac surgery & $6(18.8)$ & $2(33.3)$ \\
Other surgery & $1(3.1)$ & $1(16.7)$ \\
GI bleed & $1(3.1)$ & $0(0)$ \\
Trauma & $2(6.3)$ & $0(0)$ \\
Hemophilia & $2(6.3)$ & $2(33.3)$ \\
or FVII deficiency & & $0(0)$ \\
Other & $1(3.1)$ & $6(100)$ \\
Total & $32(100)$ &
\end{tabular}

PCC3 three factor prothrombin complex concentrate; rFVIIa recombinant Factor VII activated

\section{Results}

Thirty-eight patients were treated between November 2011 and March 2012 who met the inclusion criteria for this analysis. Six patients received rFVIIa and 32 patients received PCC3 (Table 2). The mean age of patients receiving rFVIIa and PCC3 was $57.2 \pm 19.9$ and $68.6 \pm 18$ years, respectively.

The most common indications for use included intracranial hemorrhage, typically in the presence of warfarin (75\%), cardiac and noncardiac surgery, and bleeding complications associated with factor deficiencies (i.e., Hemophilia A or B or Factor VII deficiency) (Table 3). The average dose of rFVIIa given was $3.5 \pm 3.3 \mathrm{mg}$ or $43.1 \pm 30.3 \mathrm{mcg} / \mathrm{kg}$ and the average dose of PCC 3 given was $2191 \pm 836 \mathrm{U}$ or $27.6 \pm 7.4 \mathrm{U} / \mathrm{kg}$. Repeat dosing was more common with rFVIIa use than PCC3 (33.3 vs $3.1 \%$ ) either for approved indications or as second line, salvage
Table 4 Concomitant therapy

\begin{tabular}{lcc}
\hline Concomitant therapy & PCC3 & rFVIIa \\
\hline Packed red blood cells (U) & $0(0-3)$ & $2.5(0-5)$ \\
Fresh frozen plasma (U) & $2(1-4)$ & $3(0-5.75)$ \\
Platelets (U) & $0.5(0-1)$ & $0(0-1)$ \\
Vitamin K (mg) & $10(0-10)$ & $0(0-3.75)$
\end{tabular}

Median (interquartile range)

PCC3 three factor prothrombin complex concentrate; rFVIIa recombinant Factor VII activated

treatment for patients not clinically improving on PCC3. No immunological reactions were reported. Mortality rates in patients that received rFVIIa and PCC3 were 33 and $25 \%$, respectively.

All treatment indications were compliant with the institutionally approved guidelines. All patients receiving rFVIIa therapy and $91 \%$ of PCC 3 therapy were considered dosed appropriately. Of patients considered not appropriately dosed with PCC3, two patients were over dosed and one was under dosed. Sixty-seven percent of rFVIIa and $100 \%$ of PCC3 use were for off-label indications, respectively.

Concomitant therapy was also assessed to establish patterns of use with each clotting factor and specific indications. In addition to $\mathrm{PCC} 3$ for vitamin $\mathrm{K}$ antagonist therapy reversal in patients experiencing intracranial hemorrhage, concomitant therapy most frequently included ten milligrams of intravenously administered vitamin $\mathrm{K}$ and two units of fresh frozen plasma. Prior to PCC3 administration, $62.5 \%$ of patients received $\geq 5 \mathrm{mg}$ vitamin $\mathrm{K}$ and $71.8 \%$ of patients received $\geq 2$ units of FFP. Platelet use was minimal, in patients receiving PCC 3 and was confined to surgical patients. Use of packed red blood cells and fresh frozen plasma was higher with rFVIIa associated with trauma and surgical bleeding (Table 4).

\section{Discussion}

In clinical practice at our institution, the primary use of rFVIIa and PCC 3 occurs in the setting of acute hemorrhage secondary to use of anticoagulants, surgery, and trauma. These therapies are used in addition to traditionally administered blood products and vitamin $\mathrm{K}$.

$\mathrm{PCC} 3$, in combination with vitamin $\mathrm{K}$ and fresh frozen plasma, was used primarily for acute hemorrhage, mostly intracranial, secondary to vitamin $\mathrm{K}$ antagonist use. Due to the minimal amount of factor VII in PCC3, concomitant FFP should be administered for full reversal of coagulopathies. No patients included in this analysis were taking a novel anticoagulant. Unless utilized for an FDA-approved indication, the role for rFVIIa at our institution is for 
salvage therapy in patients not responding to PCC 3 and concomitant therapies such as vitamin $\mathrm{K}$, packed red blood cells, and fresh frozen plasma.

The defined clinical benefits of administering clotting factors remain controversial. PCC4 use in anticoagulation reversal at a dose of 1,000 international units has been shown to decrease international normalized ratios 2.8 to 1.5 $(p<0.001)$ allowing for successful surgical interventions without bleeding [10]. rFVIIa use in both penetrating and blunt trauma at a total dose of $400 \mathrm{mcg} / \mathrm{kg}$ has been shown to decrease packed red blood cell transfusion requirements by 2.6 units per patient $(p=0.02)$ and the need for massive transfusion from 33 to 14 percent $(p=0.03)$ [11]. However, mortality benefit for the use of three, four, or activated PCC and rFVIIa for trauma and surgery has not been established [11-13].

The risk associated with the use of rFVIIa and PCC is primarily due to the thrombotic potential of these agents. When compared to activated PCC, there was a threefold higher relative thrombotic risk associated with rFVIIa [14]. Other safety trials comparing rFVIIa to placebo show no difference in thromboembolic events between the two treatment groups except patients greater than 65 years of age experienced higher rates of these events $[12,15,16]$. The results of the CONTROL trial showed an increased incidence of arterial thromboembolism within the first 6 days after therapy regardless of whether rFVIIa or placebo was given. The incidence of venous thromboembolism did not change with time [12].

The limited data analyzing PCC shows that it may be as effective as rFVIIa in treating major bleeding associated with surgery and trauma [17]. Despite a lack of available clinical evidence showing mortality benefit in all patients receiving rFVIIa or PCC, there is an evidence supporting the use of early hemostatic therapy in intracerebral hemorrhage [18]. The early use of 40 to $160 \mathrm{mcg} / \mathrm{kg}$ of rFVIIa in intracerebral hemorrhage has been shown to limit hematoma growth and decrease 90 day mortality from 29 to 18 percent $(p=0.02)$ [19]. The use of PCC and rFVIIa should be considered in acute, life-threatening hemorrhage as there are minimal risks associated with these therapies.

This analysis was limited as it was a single center, retrospective evaluation of a small patient population. This analysis also precedes market entry of PCC4 in the US. The number of patients that received rFVIIa was smaller than anticipated due to the trend toward preferential administration of PCC3. Due to the large variance in outcomes descriptions in the literature, mortality was the only clinical endpoint suggestive of efficacy. There is a lack of consensus in the literature regarding the definition of hemostasis following acute life-threatening hemorrhage, which creates difficulty in describing treatment efficacy. Correction of coagulation parameters (i.e., INR in warfarin- related intracranial hemorrhage), Factor VII coagulant activity, red blood cell transfusion requirements, and radiographical containment of hematoma growth have been used as surrogate endpoints [11, 17, 18, 20].

Universal indications and doses for clotting factor use during acute, life-threatening hemorrhage have not been established and guidance beyond FDA-approved indications for the majority of available products are limited [21, 22]. In patients who do not have resolution of bleeding with conventional therapy alone, there is an evidence to suggest the potential benefit of clotting factors $[1-4,5 \bullet]$. The heterogeneity of published literature indicates a need for further studies to establish optimal dosing strategies and indications of PCC and rFVIIa. Until this information is available, clotting factors should be reserved for limited, institution-approved indications based on the acuity of the patient population served and availability of literature to help guide clinical decisions. Within these institutionapproved indications should be a detailed decision tree to aid in the proper patient selection, use of concomitant therapy, and timing of clotting factor administration.

\section{Conclusion}

Factor products were used appropriately according to our institutional guidelines. rFVIIa was used infrequently at our institution, as it is reserved for either Factor VII deficiency or as salvage therapy. PCC3 use was much more common and was given with FFP and vitamin $\mathrm{K}$ for warfarin-related bleeding, per guidelines. The use of all clotting factors, particularly those given for acute, life-threatening hemorrhage, should be according to institution-approved indications based on available literature and expert opinion.

\section{Compliance with Ethics Guidelines}

Conflict of Interest None of the authors have any potential conflicts of interest relevant to this article.

Human and Animal Rights and Informed Consent This article does not contain any studies with human or animal subjects performed by any of the authors.

\section{References}

Papers of particular interest, published recently, have been highlighted as:

- Of importance

•• Of major importance

1. Bruce D, Nokes TJC. Prothrombin complex concentrate (Beriplex $\mathrm{P} / \mathrm{N}$ ) in severe bleeding: experience in a large tertiary hospital. Crit Care. 2008;12:R105. 
2. Lynn M, Jeroukhimov I, Klein Y, et al. Updates in the management of severe coagulopathy in trauma patients. Int Care Med. 2002;28:S241-7.

3. •- Vang ML, Hvas AM, Ravn HB. Urgent reversal of vitamin K antagonist therapy. Acta Anaesthesiol Scand. 2011;55:507-16. This article provides the rationale and evidence supporting the use of prothrombin complex concentrates, fresh frozen plasma, and recombinant Factor VII activated in the reversal of vitamin $K$ antagonists. Reversal of vitamin $K$ antagonists was the most common reason for factor administration at our institution.

4. Ho AMH, Dion PW, Cheng CAY, et al. A mathematical model for fresh frozen plasma transfusion strategies during major trauma resuscitation with ongoing hemorrhage. Can J Surg. 2005;48(6):470-8.

5. - Voils S. Pharmacologic interventions for the management of critical bleeding. Pharmacotherapy. 2007;27(9:2):69S-84S. This article summarizes pharmacological interventions for the management of acute bleeding due to many different coagulopathies. It provides evidence and dosing strategies for available agents.

6. Meng ZH, Wolberg AS, Monroe DM, et al. The effect of temperature and $\mathrm{pH}$ on the activity of Factor VIIa: implications for the efficacy of high-dose Factor VIIa in hypothermic and acidotic patients. J Trauma. 2003;55:886-91.

7. Paluszkiewicz P, Mayzner-Zawadzka E, Baranowski W, et al. Recommendations for the management of trauma or surgeryrelated massive blood loss. Pol Przeg Chirur. 2011;83(8):465-76.

8. Vivien B, Langeron O, Morell E, et al. Early hypocalcemia in severe trauma. Crit Care Med. 2005;33(9):1946-52.

9. Spahn DR, Cerny V, Coats TJ, et al. Management of bleeding following major trauma: a European guideline. Crit Care. 2007;11:R17.

10. Schick KS, Fertmann JM, Jauch KW, et al. Prothrombin complex concentrate in surgical patients: retrospective evaluation of vitamin $\mathrm{K}$ antagonist reversal and treatment of severe bleeding. Crit Care. 2009;13:R191.

11. Boffard KD, Riou B, Warren B, et al. Recombinant Factor VIIa as adjunctive therapy for bleeding control in severely injured trauma patients: two parallel randomized, placebo-controlled, double-blind clinical trials. J Trauma. 2005;59:8-18.
12. Dutton RP, Parr M, Tortella BJ, et al. Recombinant activated Factor VII safety in trauma patients: results from the control trial. J Trauma. 2011;71:12-9.

13. Sarode R, Milling TJ, Refaai MA, et al. Efficacy and safety of a 4-factor prothrombin complex concentrate in patients on vitamin $\mathrm{K}$ antagonists presenting with major bleeding: a randomized, plasma-controlled, phase IIIb study. Circulation. 2013;128: $1234-43$.

14. Levy JH, Fingerhut A, Brott T, et al. Recombinant Factor VIIa in patients with coagulopathy secondary to anticoagulant therapy, cirrhosis, or severe traumatic injury: review of safety profile. Transfusion. 2006;46:919-33.

15. Levi M, Levy JH, Andersen HF, et al. Safety of recombinant activated Factor VII in randomized clinical trials. NEJM. 2010;363:1791-800.

16. Aledort LM. Comparative thrombotic event incidence after infusion of recombinant Factor VIIa versus Factor VIII inhibitor bypass activity. J Thromb Haemost. 2004;2:1700-8.

17. Pinner NA, Hurdle AC, Oliphant C, et al. Treatment of warfarinrelated intracranial hemorrhage: a comparison of prothrombin complex concentrate and recombinant activated Factor VII. World Neurosurg. 2010;74:631-5.

18. Mayer SA. Intracerebral hemorrhage: natural history and rationale of ultra-early hemostatic therapy. Int Care Med. 2002;28: S235-40.

19. Mayer SA, Brun NC, Begtrup K, et al. Recombinant activated Factor VII for acute intracerebral hemorrhage. NEJM. 2005;352: 777-85.

20. Morrissey JH, Macik BG, Neuenschwander PF, et al. Quantitation of activated Factor VII levels in plasma using a tissue factor mutant selectively deficient in promoting Factor VII activation. Blood. 1993;3:734-44.

21. Hedner U, Lee CA. First 20 years with recombinant FVIIa (NovoSeven). Haemophilia. 2011;17:e172-82.

22. Kerebel D, Joly LM, Honnart D, et al. A French multicenter randomized trial comparing two dose-regimens of prothrombin complex concentrate in urgent anticoagulation reversal. Crit Care. 2013;17:R4. 